\title{
The Role of Sense of Community in Mediation between Positive Emotions and Attitudes toward Brand and Message
}

\author{
Saoussen Abdelkader and Néji Bouslama
}

Faculty of Economics and Management of Tunis, Tunisia

\begin{abstract}
Correspondence should be addressed to: Saoussen Abdelkader; saoussen_abdelkader@yahoo.fr
\end{abstract}
Received Date: 24 December 2012; Accepted Date: 28 December 2013; Published Date: 31 January 2014

Academic Editor: Tahar Lazhar Ayed

Copyright (C) 2014 Saoussen Abdelkader and Néji Bouslama. Distributed under Creative Commons CC-BY 3.0

\begin{abstract}
The aim of this study is to examine the mediating role of sense of community of members of a group in the impact of affective responses to advertising on attitudes toward the brand and message. To this end, a study on 380 adolescents active on Facebook is conducted. The results indicate that positive emotions felt toward an advertising message oriented to the community under study directly and positively affected their attitude toward the message. We found also it directly and positively affects on sense of community. Moreover, we found that attitude toward the message and sense of community mediate an indirect positive effect on attitude toward Facebook.
\end{abstract}

Keywords: Positive emotions, attitude toward the brand, attitude toward the message, sense of community.

\section{Introduction}

In advertising, several marketing studies have largely investigated emotions to show their positive effect on consumers' responses to ads (Holbrook and Schimp, 1981 cited by De barnier V. (2002), p13) and consequently on advertising efficiency.

Previous research tried to understand the role of emotions felt in response to advertising stimuli in explaining behavior, in particular of consumer and target groups' attitudes, through demographic, psychographic and/or psychological criteria. This is done for segmentation purposes, i.e. the segments are the researcher's own construction. Our study, qualified as postmodern, aims at investigating the interactions between adolescents who are distinguished by a desire to belong expressed through the concept of "sense of community".

Taking into account how postmodern adolescents represent emotions is an appropriate way to better understand and apprehend modern consumer behaviour. At this level, it becomes necessary then to measure the impact of emotions felt toward an advertising stimulus on attitudes of a community of adolescents on the message and the brand and to show the role of sense of community in this impact. 
This study is not the first of its kind to focus on the impact of affective components on responses to advertising in terms of attitudes toward the brand and the message. It is not as well the first study to examine sense of community of adolescents and its impact on their behaviour. Nevertheless, this study is unique in considering an integrative model in which variables which have been studied separately by previous research are included together.

Then, this paper is structured as follows. A first section presents the literature review on the study of emotions in advertising and sense of community of adolescents. Then, our theoretical framework and research hypotheses are reformulated. A second section presents the methodology of our study. Finally, the last section presents and examines the results.

\section{Review of the Literature}

\section{Efficiency of Emotions in Advertising}

\section{Defining Emotions}

Researchers found it difficult to agree on a definition of emotions. This explains the multitude of definitions, sometimes contradictory, given to the same concept of emotion. This disagreement bears on the theories endorsed by some authors in this field of study.

Therefore, the definition given and considered as the most general and which takes into account the fact that emotion is a particularly important set of affective states is that of Gouteron (1995, cited by Lemoine J.F, 2001, p51) who considers emotion as "a momentary, multiform and more or less intense affective reaction resulting from a disturbing factor external to the individual".

This definition assumes that emotion seems to result in a determined situation and particularly discovered having some degree of intensity associated to a stimulating object or event exogenous to the individual and which disrupts a stable state.
In this case, the relationship between the individual and emotional situation or stimulus may be characterised by a positive or negative landmark at any intensity degree. Then, a positive emotion is associated to an additional behaviour oriented to some object while a negative emotion is associated to a defensive or resisting behaviour oriented to threatening or disgusting stimuli (Schneirla 1959, cited by Hazlett R.L and Hazlett S.Y, 1999, p9).

\section{Importance of and Interest in Emotions}

During the 1980s, a particular interest in the role of emotions knew a considerable development in consumer research. Researchers, convinced that this issue is a promising field of studying consumer behavior, did not limit themselves to the study of this concept in a consumption context (Holbrook and Hirshman, 1982), but far beyond that, they consider advertising as a fertile field of study that attracted researchers from psychology and marketing disciplines (Hill and Mazis, 1986; Zeitlin and Westwood, 1986; Aaker, Stayman and Vezina, 1988; Batra and Holbrook, 1990, cited in De Barnier V. 2002, p 82).

Accordingly, researchers of the consequences of affective responses felt by individual toward advertising have become the main concern of all researchers who focused their attention on conceptualizing the process of persuasion in relation to emotions and their effects on consumers' responses to ads.

These responses to ads may relate to different measures targeted to examining efficiency of advertising. These measures try for instance to see whether the audience has been accurately exposed to advertising or to measure the brand's entry rate and repurchasing rate. In this line of thinking, several measures and instruments have been put at the disposal of advertising professionals like IPSOS's display barometer (Barometre d'Affichage), campaign balance, impact score (IFOP), buy test (SOFRES)... (Reunier S, 2000). 
Nevertheless, as Moser (1998) reminds us, few researchers affirm that advertising reaches direct and immediate results like purchasing the product. Advertising triggers in consumers a set of intermediate responses that may indicate advertising efficiency. Then, measurement of these responses seems necessary to understand the impact of advertising. Since the 1980s, the premise that emotions may influence responses to ads has gathered momentum and attracted researchers' attention. If at some point in time these researchers had their focus dislocated, in spite of this it seemed that emotions may act at all levels of advertising reach (cognitive, affective and connotative) to insure its efficiency.

These different levels represent the set of responses to advertising. However, several researchers opted for the use of measuring affective responses to advertising to examine the impact of emotions on responses to advertising. In these terms Vakratasas and Ambler (1999) cited by Rieunier S. (2000, p 27) have put it: "affective responses to advertising may be classified into two categories: that which leads to formation of attitudes toward the brand and that which leads to formation of attitudes toward the ad or toward an expression that markets the ad itself".

\section{Behaviour of Postmodern Groups and Sense of Community: Case of Adolescents}

After the postmodern era and the new forms of social links, a new need is born in consumers characterized by the development of a sense of belonging to a group, putting at the front the formation of new social links between members of that group. This is termed "sense of community". This concept summarises a sense of belonging to a community and an awareness of that belonging (Heller and Aliii, 1984, cited by Kim and Kho, 2003; Newbrough and Chavis, 1986 cited by Ben Yahia I. (2009, p25)).

Postmodern groups are known then by this sense of community which is currently one of the most studied psychological constructs and represents the most original and most significant contribution to sociology research (Tartaglia, 2006 in Ben Yahia I., 2009, p 24)). The focus on this construct stems from its ability to plan and evaluate social actions. As predicted by Sarason (1974) cited by Tartaglia S. (2006, p25), sense of community relates to varied indices of the quality of daily life, like satisfaction (Prezza and Costantini, 1998), perception of peace and security (Perkins and Taylor, 1996), and social and political engagement (Chavis and Wondersman, 1990 ; Davidson and Cotter, 1989 ; Florin and Wondersman, 1954).

Studies of groups under a postmodern paradigm have been related to some behavioural aspects in several disciplines like that of leisure; exchange of sports cards (Baker and Martin, 2000), Baseball games (Holt, 1995), and parachuting (Celsi, Rose and Leigh, 1993). Other studies join the studies on experiential marketing of Holbrook and Hirschman (1982) examining the type of relationship between postmodern consumers and the brand and the experience invoked by the brand (Schouten, Mc Alexander and Koening, 2002, Bagozzi and Dolakhia, 2001, Fournier, Schouten and Mc Alexander, 2000).

These marketing studies did not directly examine the role of sense of community in explaining postmodern consumers' behaviour. Nevertheless, they did so indirectly. The domaine which showed much interest in this relationship is that of sociology. Sense of community has been studied to show its role in understanding postmodern groups' behaviour, mainly in matters of social development and specifically on adolescents.

Adolescence is often known by a phase where individuals start to explore and examine psychological spheres in view of discovering their reason to be and the manner with which they adjust themselves to their social reality (Laurence Steinberg and Amanda Sheffield Morris (2001, p91). This latter orientation may help them create a social identity manifested in the considerable influence of the group as well as any other behaviour of the group (See 
Brewer and Brown, 1998 cited by Wood W. (2000, p 557)).

Studies on adolescents' development suggest that adolescents differently benefit from opportunities of being involved in a community (Catalano, Loeber and Mc Kinney, 1999; Maton, 1990; Youniss, McLellan and Yates, 1997), yet most studies on sense of community and social cohesion have neglected adolescents experiences.

The results of a wide range of research on sense of community in adults which, showed the importance of participation in community, neighbourhood or work activities, have encouraged other researchers to explore the relevance of this concept to adolescents in contexts of neighbourhood or school which are the communities in which adolescents spend most of their time (Pretty Conroy Grace M.H, Andrewes Lisa, Collett Chris, 1994, p 347).

These studies assumed that sense of community is involved in adolescents' development the same way it is for adults. During adolescence, several sense of communities develop and play an important role in understanding their behaviour. Then, the first sense of community, after family, is formed at school which help facilitate or hinder success of adolescence development (Cartlard et al, 2003, Roeser, Midgley and Urdan, 1996; Shaps and Solomom, 2003, cited in Alessio Vieno, Massimo Santinello, Massimiliano Pastore, Douglas Perkins (2007, 179)).

Impact of Emotions on Attitudes toward the Brand and Message and on Sense of Community of Members of a Group: Our Model and Research Hypotheses

\section{Impact of Emotions on Attitudes toward the Brand and Message}

Several researchers have examined the impact of emotions on responses to advertising. Most of them focused on the affective responses of attitude toward the brand and message. Graillot L assumes after Mitchell and Olson (1981) that affective responses to advertising influence attitude toward the brand. Moreover, the concept of attitude toward the message is fundamental in the advertising persuasion process as it helps capture the affective responses triggered by an advertising message (Lutz, Mac Kenzie and Belch 1983 in Graillot L. (1998, p 18)) and influences therefore attitude toward the brand.

At this level, impact of emotions on attitude toward the message seems to strongly motivate consumer behavior, helping in the process the formation and change of attitudes. Then, the study of emotions determinacy is based on measuring this impact, as Rieunier S. (2002) in Graillot L, (1998, p 18) puts it: "measurement of these intermediate responses (attitude toward the brand and attitude toward the message) which may indicate advertising efficiency, seem relevant to understand the mechanisms of advertising impact, and therefore the impact of emotions in advertising".

These studies conclude with the general hypothesis of the impact of affective responses (emotions) on affective responses to advertising (attitude toward the brand and message).

The difficulty in identifying the nature of the effect, direct or indirect, linking emotions and attitudes toward the message have led some researchers to adapt their methodology by grouping together emotions in terms of their valence, examining the impact of positive emotions vs. Negative emotions (De Barnier V, 2002).

Edell and Burke (1987) referring to Ben Chikh Ahmed S. (2003, p76, 77) proposed that emotions result from exposure to advertising and that these emotional responses may be positive or negative at the same time and that they may influence the nature of advertising post-processing. They add also that these emotional responses may predict attitudes toward advertising and the brand, for known or unknown brands alike. 
The results under this assumption indicated that positive affective responses positively influence Aad and Ab (Batra and Ray 1986; Holbrook and Batra 1987; Aaker, Stayman and Hagerty 1986). Howver, research on negative emotions still raises controversies on these relationships. We align ourselves with the first set of results and propose the following research hypotheses:

\section{H1: positive emotions positively influence Aad \\ H2: positive emotions positively influence $A b$}

H3: attitude toward message positively influences attitude toward the brand

\section{Impact of Emotions on Sense of Community}

The concept sense of community was not the object of marketing or advertising studies in general nor was affective responses in particular. Therefore, we will try to examine the relationship between emotions and sense of community.

Definition of psychological sense of community has often been controversial. According to Balcazar F. (1997), in a Society for Community Research and Action seminar on understanding community from a psychological perspective, the participants considered that "sense of community is conceptualised as cognition, a behaviour, an individual affective state, a characteristic of the environment or even a spiritual dimension".

We therefore can found our research hypotheses on the different studies conducted on the impact of emotions on for example cognition (Zajonc, 1980, Zajonc and Markus, 1982), on behaviour and attitudes (Holbrook and Hirshman 1982 cited by Sophie Rieunier, 2002) and in general on all previously mentioned processes (Gardner, 1985). Hence, emotions may be considered as a factor of sense of community.
Sense of community may also refer to a dimension of the dimensions of psychological sense of community developed by Mc Millan and Chavis (1986) which is self-identification (Fisher and Sonn, 1999; Puddifoot, 1995).

According to social identity theory (Tajfel, and Turner, 1979; Abrams and Hogg, 1990), self-identification is a cognitive concept. The individual identifies him/herself with others when he/she believes that he/she believes that there is a psychological proximity between him/herself and the other. We can then found our research hypotheses on the studies conducted on supremacy of emotions on cognition (James, 1980; Zajonc, 1980) the theory of Zajonc rests on the fact that the first reaction to an; object or a person is an emotional reaction, knwing that emotional and cognitive systems are partially independent and if there is an influence, emotions have the supremacy (Zajonc, 1980 in Charbti M., 2006, p 45). This latter assumption confirms then that emotion is a factor behind self-identification and may positively and negatively influence it. Then, if emotion felt to a message is positive, the individual will tend to identify him/herself with the character in the ad, with the product and with the context in general. By opposition, there may be repulsion.

Against this assumption, we can deduce the impact of emotions on sense of community and we formulate the following research hypothesis:

\section{Impact of Sense of Community on Attitudes toward the Brand (Ab) and the Message (Aad)}

\section{The Impact on Aad:}

The desire to belong to a community expressed by members of a group is nothing but one of the characteristics of postmodern culture, which is more and more present in advertising. In advertising, "we no longer look to persuade of a product's advantage but to entertain the relationship we have with the target, no longer a hierarchical relationship between 
a sender and a receiver, but a pair-wise relationship founded on proximity, agreement and complicity" (Riou N., 2003, p 89). These characteristics create a sense of community between individuals, reflecting some degree of closeness with the characters and experiences presented in an ad. However, Aad or judgment of an advertising stimulus often relates to a cognitive element and an affective element. Then, we cannot exclude the effect of emotions triggered by advertising and felt by the community. This leads us to the following research hypotheses:

\section{H5: Sense of community positively influences Aad.}

\section{The Impact on $A b$}

In communities, members are connected through social relationships that bear on the social nature of these connections. According to Remy E. (2001), «community marketing actions consist of detecting communities around common passions and practices with the aim of associating to the offer a link value". Moreover, according to Cova B. (1995) in Cova B. and Badot 0. (1995), the link becomes the main object and superior to the goods. This suggests also that members do not consume the goods for the sake of the "goods" but the link it proposes and the value it ads to sense of community. Then, this latter may influence members' behaviour toward what they consume. The more they feel the link, the more they react to the offer.

According to the social relationships model, this latter assumption is justified by the relationship between consumers and the brand. According to Aggarwal (2004) in Augou M.O. (2009), this model assumes that "in a relationship, partners are evaluated according to the group norms. Applied to the brand-consumers relationship, this assumes that purchasing a brand may reflect social relationships and that the to-be-purchased brands may be determined the group's social norms".

Sense of community then determines behaviour toward the goods (brand/product).

\section{Hence, H6: sense of community positively influences $A b$}

\section{The Mediating Role of Sense of Community between Emotions and Attitudes}

Special interest encouraged researchers to focus on the role of emotions in consumers' responses. Most researchers started to consider affective responses triggered by advertising as determinants of Aad (Aaker and Stayman and Hagerty, 1986; Batra and Ray, 1986; Hill and Mazis 86; Edell and Burke, 1987, Kho and Stout, 1993) and brands (Aaker and stayman, and Hagerty, 1986; Hill and Mazis, Staymen and Aaker, 1988; Burke and Edell, 1989; Homer and Yoon, 1992). This set of studies reached interesting results on the effect between emotions and attitudes which made possible through different mediators like brand cognition and message cognition (Edell and Burke, 1987; Batra and Edell, 1989) in Edell J.A and Burke M.C (1987).

However, community-wise and when the message targets members (goods, services, particular interest), sense of community expressed by feeling of belonging and emotional attachment, influence and satisfaction of needs may play an important role in the effect of emotions on attitudes.

Sense of community which summarises members' judgements is presented as mediating these effects once it may be influenced by emotions and may by itself influence members' behaviour.

Therefore, in addition to the direct effects of emotions, we can hypothesise for an additional indirect effect that goes through a cognitive dimension, i.e. the community judgements.

\section{Hence, H7: Sense of community mediates the effect of emotions on attitudes}

Our model and research hypotheses are depicted in the following Figure. 


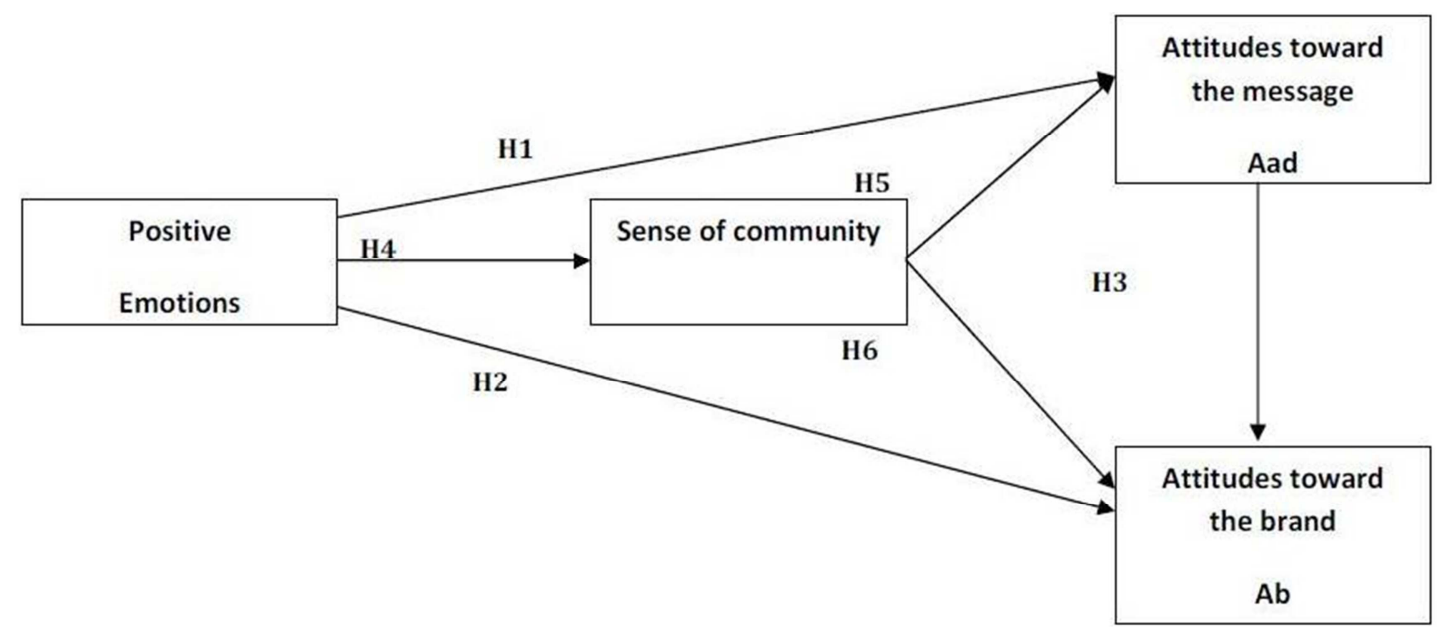

Figure 1: The Research Model

\section{Methodology}

\section{- Choice of Advertising Stimulus}

The chosen advertising message should respect the necessary conditions. First, it should be emotionally loaded to be able to provoke positive emotions in adolescents. Second, it should correspond to a product or service that is shared by the community members (community product or service). Then, the chosen products or services should represent a community relationship value with a particular significance to the target useable for social than functional or utilitarian purposes, helping them satisfy their self-identification to the community.

We chose an internationally-known visual on Facebook. It is a picture which depicts different people from different cultures forming a band sharing positive emotions (pleasure, joy, happiness ...), gathered together to say the same thing: Facebook.

\section{- Choice of the Target}

An adolescent consumer may be the best example of an individual full of sense of community given his/her age which is known for the drive to change and progress. Adolescence age is the age of identity quest, self- esteem and social recognition, found in sense of community shared with others.

\section{- Sampling Method}

The chosen sampling method is that of quota-based sampling, i.e. "a sampling that respects the known characteristic of our population" (Réjean Savard, 1988). We chose among the total population those who have specific characteristics or fixed quotas to insure a great level of representativeness of the population. In our case, the quota is having an age between 12 and 17 years. We were able to interview 380 individuals.

\section{- Data Collection Method and Instruments}

In this study, we aim at discovering the role of sense of community in the impact of emotions on attitudes. We proceeded then through conducting a survey, the most appropriate method to collect our data. The instrument used is a questionnaire.

\section{- Experimental Design}

The experiment took place in different locations where adolescents are available: cultural centers, movie theatres, leisure parks and some high schools in Tunisia. The informants have been exposed once to the advertising visual, then they were given time to express their emotions, judgement of the message, the web site and their sense of community. 


\section{- Measurement of variables}

- The Independent Variable: to measure emotions felt about an advertising message, we chose the scale of Edell and Burke (1987, p 424) «Feelings toward Ads », which we translated into French. The scale includes positive and negative emotions toward the given advertising message and which influence attitudes toward the brand ad message (Edell and Burke, 1987 in William 0. Bearden , Richard G. Netemeyer, 1999, p 283). We limited ourselves to the positive emotions of this 45-item, 5-point likert scale.

- The Dependent Variables: to measure attitude toward the brand (web site) and message, we opted for the standard one-dimensional scales of Holbrook and Batra (1987, p 411), translated into French. These scales contain each 4 items scored on a 5-point liker scale.

- The Mediating Variable: to measure sense of community in Facebook community members, we used the scale of Koh and Kim (2003). It contains 3 dimensions (belonging, influence and immersion), containing each 4 items scored on a 5-point likert scale. We added to this latter scale 4 items representing to dimensions of confidence, self-identification and pleasure, taken from an exploratory study on sense of community in adolescents that we conducted in response to critics of using scales conceived for adults to and extrapolated on adolescents.

\section{Analysis and Interpretation of Reults}

\section{- Results of the Exploratory Factor Analysis (EFA)}

The exploratory factor analysis we conducted on our set of variables helped us identify the one or multidimensional structure of the different measurement scales. First, we conducted Kaiser-MeyerOlkin's sampling adequacy test (KMO). The retained value is between 0.7 and 0.8 indicating an adequate factor analysis. Second, we run a Principal Component Analysis (PCA) over a sample of 100 informants. We obtained for each scale items whose factor loadings and communalities are $>0.5$. Finally, we conducted a reliability analysis for the set of scales, the result of which is Cronbach's Alpha superior to 0.7 .

\section{- Results of the Confirmatory Factor Analysis (CFA)}

To validate the structures obtained through EFA, we conducted a confirmatory factor analysis which showed a one-dimensional structure for the scales of attitude toward the brand ( 2 items) and attitude toward the message (4 items), a three-dimensional structure for the scale of emotions (pleasure, warmth and arousal) and for sense of community scale (belonging, immersion and confidence). We checked convergent validity and reliability of our measurement scales through Joreskog's rho and convergent validity rho (>0.5) which are significant. These coefficients are reported in the following table (except for the Ab scale which is under-specified):

Table 1: Reliability and Convergent Validity of Measurement Scales

\begin{tabular}{|l|l|l|l|}
\hline Scales & Factors & Jôreskog's Rho & Rho of covergent validity \\
\hline Attitude toward the message & Aad & 0.803 & 0.507 \\
\hline \multirow{3}{*}{ Positive emotions } & Pleasure & 0.913 & 0.781 \\
\cline { 2 - 4 } & Arousal & 0.945 & 0.842 \\
\cline { 2 - 4 } & Warmth & 0.918 & 0.737 \\
\hline \multirow{3}{*}{ Sense of community } & Belonging & 0.790 & 0.558 \\
\cline { 2 - 4 } & Immersion & 0.794 & 0.573 \\
\cline { 2 - 4 } & Confidence & 0.838 & 0.722 \\
\hline
\end{tabular}


Discriminant validity is checked also as all Rho coefficients of convergent validity of the scales are superior to squared correlation of all constructs. The results are reported in the following table:

Table 2: Discriminant Validity of the Model (B)

\begin{tabular}{|l|l|l|l|l|l|l|l|l|}
\hline & Abpost & Aad & Pleasure & Arousal & Warmth & belong & Immer & Confi \\
\hline Abpost & $\mathbf{0 . 7 1 4}$ & & & & & & & \\
\hline Aad & 0.017 & $\mathbf{0 . 5 2 0}$ & & & & & & \\
\hline Pleasure & 0.029 & 0.001 & $\mathbf{0 . 6 8 1}$ & & & & & \\
\hline Arousal & -0.110 & -0.229 & 0.587 & $\mathbf{0 . 7 9 6}$ & & & & \\
\hline Warmth & 0.017 & 0.172 & -0.045 & -0.183 & $\mathbf{0 . 7 3 7}$ & & & \\
\hline Belonging & -0.063 & -0.049 & 0.096 & 0.351 & -0.141 & $\mathbf{0 . 7 3 4}$ & & \\
\hline Immersion & -0.072 & -0.120 & 0.045 & 0.106 & -0.003 & 0.044 & $\mathbf{0 . 7 2 7}$ & \\
\hline Confidence & -0.099 & 0.141 & -0.208 & 0.014 & -0.167 & 0.488 & 0.015 & $\mathbf{0 . 7 2 9}$ \\
\hline
\end{tabular}

\section{- Global Model}

Fit indices are satisfactory even if some approximate threshold levels and indicate the good fit quality of the model. RMR, AGFI, and RMSEA coefficients are within the norms even if the GFI coefficient is under 0.9. Our model responds also to parsimony condition as BIC coefficient is significant $(<\mathrm{BIC}$ of the saturated model) and the standardized Chi-square is under $<$ 5 , which respects the norms.

The following table reports these results:

Table 3: Global Model Fit

\begin{tabular}{|l|l|l|l|l|l|l|l|l|}
\hline $\mathrm{X}^{2}$ & $\mathrm{X}^{2} / \mathrm{ddl}$ & $\mathrm{GFI}$ & AGFI & RMR & RMSEA & TLI & CFI & BIC \\
\hline $\begin{array}{l}\text { 623.251 } \\
\text { DD181 } \\
\text { P 0.000 }\end{array}$ & 3.443 & 0.879 & 0.831 & 0.034 & 0.08 & 0.831 & 0.892 & $1050.943 / 1502.863$ \\
\hline
\end{tabular}

\section{- Test of the Structural Model}

The results indicate that the structural model is parsimonious with a BIC value < of the saturated model and very significant Chi-square values. Absolute and incremental values do not all of them show good estimates, yet they are acceptable and indicate a good fit quality of the structural model.

The results are reported in the following table: 
Table 4: CFA of the Structural Model of Positive Emotions

\begin{tabular}{|c|c|c|c|c|}
\hline & Structural links & CR & $\mathbf{P}$ \\
\hline Abpost & Warmth & 0.066 & 1.040 & 0.298 \\
\hline Abpost & Arousal & 0.123 & 2.071 & 0.038 \\
\hline Abpost & Pleasure & 0.085 & 1.264 & 0.206 \\
\hline Abpost & Sense of community & 0.547 & 2.556 & 0.038 \\
\hline Abpost & Aad & 0.412 & 1.168 & 0.037 \\
\hline Aad & Warmth & 0.142 & 2.428 & 0.015 \\
\hline Aad & Arousal & 0.330 & 5.840 & 0.000 \\
\hline Aad & Pleasure & 0.189 & 2.618 & 0.009 \\
\hline Aad & Sense of community & 0.137 & 1.665 & 0.096 \\
\hline Warmth & Sense of community & 0.414 & 3.106 & 0.002 \\
\hline Arousal & Sense of community & 0.265 & 4.187 & 0.000 \\
\hline Pleasure & Sense of community & 0.432 & 2.748 & 0.006 \\
\hline & Chi-square & 793.497 & & \\
\hline & Degrees of freedom & 194 & & \\
\hline & $\mathrm{P}$ & 0.000 & & \\
\hline & $\begin{array}{l}\text { Chi-square/ Degrees of } \\
\text { freedom }\end{array}$ & 4.090 & & \\
\hline & GFI & 0.845 & & \\
\hline & AGFI & 0.798 & & \\
\hline & RMSEA & 0.090 & & \\
\hline & RMR & 0.050 & & \\
\hline & TLI & 0.826 & & \\
\hline & CFI & 0.854 & & \\
\hline & BIC/saturated model & $1143.967 / 1502.8$ & & \\
\hline
\end{tabular}

\section{- Testing Our Research Hypotheses}

The different relationships hypothesized by the model have been tested using structural equation modeling conducted on Amos18 software.

\section{- Testing Relationship \\ H1: Emotions/Aad}

To test the relationship between positive emotions and attitude toward the message, we analyzed the structural links knowing that the variable positive emotions is represented by three dimensions: pleasure, arousal and warmth. Then, three relationships have been tested as reported in the following table:

Table 5: Results of $\mathrm{H1}$

\begin{tabular}{|l|l|l|l|}
\hline & $\begin{array}{l}\text { Standardized regression } \\
\text { coefficient }\end{array}$ & cr & $\mathrm{p}$ \\
\hline Pleasure-Aad & 0.121 & 2.041 & 0.041 \\
\hline Arousal-Aad & 0.317 & 3.799 & 0.000 \\
\hline Warmth-Aad & 0.198 & 2.405 & 0.016 \\
\hline
\end{tabular}

Analysis of these results confirms the validity of $\mathrm{H} 1$ as all dimensions of emotions positively influenced Aad. Then, individuals exposed to an advertising message targeting their community feel positive emotions which positively influence their judgement of the message. 
We used two indicators to test the second hypothesis.

- Testing H2: Emotions/Ab Relationship

The results are summarized as follows:

Table 6: Results of $\mathrm{H} 2$

\begin{tabular}{|l|l|l|l|}
\hline & $\begin{array}{l}\text { Standardized regression } \\
\text { coefficient }\end{array}$ & cr & $\mathrm{p}$ \\
\hline Pleasure-Aad & 0.067 & 1.110 & 0.267 \\
\hline Arousal-Aad & 0.208 & 2.067 & 0.039 \\
\hline Warmth-Aad & 0.162 & 1.732 & 0.083 \\
\hline
\end{tabular}

Analysis of the different relationships shows that positive emotions of pleasure and warmth have no positive effect on attitude toward the brand as all indicators are not significant. These relationships do not support the theory which assumes a positive relationship between emotions and attitude toward the brand. We can just approve the positive and significant relationship between the positive emotion's dimension of arousal and attitude toward the brand.

\section{- Testing H3: Aad/Ab}

The relationship between the independent variable attitude toward the message and the dependent variable attitude toward the brand (Facebook) bears a positive effect between these two variables. This result supports the theory and indicates that attitude toward the message influences attitude toward the brand. Accordingly, an individual judgment of the advertising message influences his/her judgment of the brand.

The following table reports the results of this relationship:

Table 7: Results of $\mathrm{H3}$

\begin{tabular}{|l|l|l|l|}
\hline & $\begin{array}{l}\text { Standardized } \\
\text { coefficient }\end{array}$ & regression & cr \\
\hline Aad $-\mathrm{Ab}$ & 0.644 & 3.619 & 0.026 \\
\hline
\end{tabular}

\section{- Testing H4: Emotions/ Sense of Community (SC)}

To test this relationship, we examined the effect of the three dimensions of emotions on the dependent variable sense of community (second order). The following table reports the different results:

Table 8: Results of $\mathrm{H4}$

\begin{tabular}{|l|l|l|l|}
\hline & Standardized regression coefficient & cr & $\mathrm{p}$ \\
\hline Pleasure-Aad & 0.569 & 2.616 & 0.038 \\
\hline Arousal-Aad & 0.645 & 2.692 & 0.049 \\
\hline Warmth-Aad & 0.658 & 2.664 & 0.026 \\
\hline
\end{tabular}

With reference to these results, we can validate $\mathrm{H} 4$ as all dimensions of emotions have a positive impact on sense of community. We can conclude that individuals exposed to an advertising stimulus feel positive emotions which positively influence their sense of community. This latter variable is reinforced by the effect of emotions. 


\section{- Testing H5: Sense of Community/Aad}

This hypothesis stipulates that sense of community positively influences attitude toward the message. The structural link hypothesis which assumes that evaluation of the advertising message depends on strength of sense of community. This leads us to reject H5. The results are reported in the following table:

between these two variables is not significant. This result leads us to reject the

\section{Table 9: Results of $\mathrm{H5}$}

\begin{tabular}{|l|l|l|l|}
\hline & $\begin{array}{l}\text { Standardized regression } \\
\text { coefficient }\end{array}$ & $\mathrm{cr}$ & $\mathrm{p}$ \\
\hline $\begin{array}{l}\text { Sense of } \\
\text { community -Aad }\end{array}$ & 2.446 & 0.895 & 0.371 \\
\hline
\end{tabular}

\section{- Testing H6: Sense of Community - Ab}

We tested the relationship between the dependent variable attitude toward the brand and the independent variable sense of community. The results point to a significant positive relationship. This supports the hypothesis which assumes that individuals evaluate the brand in terms of their sense of community. The higher this latter is, the more positive is the attitude. The following table reports the results:

Table 10: Results of $\mathbf{H 6}$

\begin{tabular}{|l|l|l|l|}
\hline & $\begin{array}{l}\text { Standardized regression } \\
\text { coefficient }\end{array}$ & $\mathrm{cr}$ & $\mathrm{p}$ \\
\hline $\begin{array}{l}\text { Sense of community - } \\
\mathrm{Ab}\end{array}$ & 0.535 & 3.339 & 0.035 \\
\hline
\end{tabular}

\section{- Testing H7: Mediation of Sense of Community}

We examined whether sense of community is a mediating variable between emotions and attitudes toward the message (H7.1) and attitude toward the brand (H7.2). We refer to the work of Zhao, Lynch and Chen (2009, p 14) to detect mediation and its role. The results of these studies are summarized in the following figure and table:

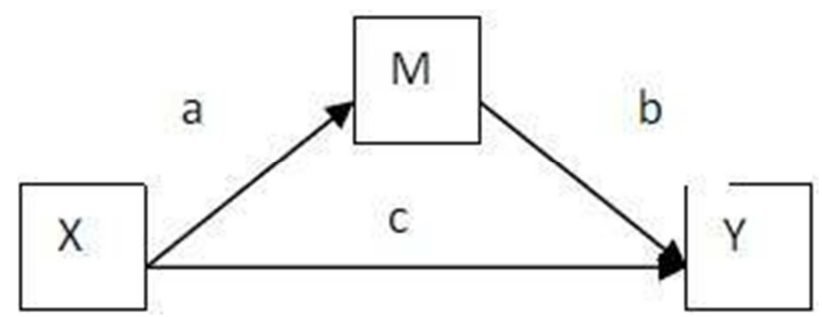

Figure 2: Mediation Scheme

Table 11: Types of Mediation according to Zhao, Lynch and Chen (2009)

\begin{tabular}{|l|l|}
\hline Mediation type & Label \\
\hline
\end{tabular}




\begin{tabular}{|l|l|}
\hline Complementary Mediation & $\begin{array}{l}\text { The mediating effects of (a*b) and the direct } \\
\text { effect c exist and all point to the same } \\
\text { direction. }\end{array}$ \\
\hline Competitive Mediation & $\begin{array}{l}\text { The mediating effects of (a*b) and the direct } \\
\text { effect c exist and all point to opposite } \\
\text { directions. }\end{array}$ \\
\hline Indirect-Only Mediation & $\begin{array}{l}\text { Only the indirect mediating effects (a*b) exist. } \\
\text { Direct-Only Non-Mediation } \\
\text { effects are not significant. }\end{array}$ \\
\hline No-Effect Non-Mediation & $\begin{array}{l}\text { Neither the direct effects nor the indirect } \\
\text { effects exist. }\end{array}$ \\
\hline
\end{tabular}

With reference to these results, the mediating role of sense of community (variable $M$ ) between the independent variable emotions $(\mathrm{X})$ and the dependent variable the message (Y) fits the category " direct only non mediation ». This means that there is only a direct effect of emotions on Aad and the indirect effect of sense of community on Aad is not significant, although effect of emotions on sense of community is significant.

Mediation of sense of community (M) between emotions $(\mathrm{X})$ and attitude toward the brand (Y) fits the category «Indirect only mediation » as there are only indirect effects. Emotions significantly influence sense of community (a), which in turn significantly influences attitude toward the brand (b). However, the direct effect is not significant.

\section{- Discussion of the Results}

With reference to results, we notice that positive emotions have a positive and direct impact on attitude toward the message only (H1) and not on the brand. Then, the dimensions "pleasure», « warmth » and "arousal» determine this effect (values of $\mathrm{p}<0.005$ ). Therefore, $\mathbf{H 1}$ is validated.

These dimensions have a positive effect on Aad, suggesting that the more adolescents are pleased, inspired, happy ... the more positive their attitude toward the message. The positive emotions felt by a receiver to an advertising message induce them to develop a positive reaction to the ad, as this latter carries a positive image creating proximity with the receiver. This latter tends to appreciate and internalizes the advertising stimulus. This assumption is supported by the literature which confirms that positive affective responses positively influence Aad (Batra and Ray, 1986; Holbrook and Batra, 1987; Aaker and Stayman and Hagerty, 1986 cited by Virginie de barnier, 2002).

However, our results seem to indicate that positive emotions have no effect on attitude toward the Facebook site (H2) as $p$ values are not < 0.005; except Arousel dimension. Therefore, $\mathbf{H 2}$ is rejected. This finding means that judging or evaluating this site does not depend on the receiver's feelings, but maybe on other factors. This line of thinking may be justified by Fishbein's theory which assumes that "beliefs about the properties of an object, attributes, which are important for the individual and more or less well evaluated by this latter determine attitude toward that object" (Fishbein, 1963 cited by Maria Mercanti Guerin, 2005). Then, it is cognitive factors which determine $\mathrm{Ab}$. Moreover, we should remind that Facebook is familiar enough for adolescents and therefore its judgment does not depend on feelings or emotions felt by receivers the way they feel about unfamiliar products. In this regard, Edell and Burke (1987) cited by Maria Mercanti Guerin (2005) show in the case of unknown products that the considerable contribution of feelings to forming beliefs about a brand determines attitude toward the brand.

Another perspective may support the obtained results, which is that of Shimp (1981). Shimp distinguishes two mechanisms which influence the choice of a brand in an advertising condition, "the first mechanism of interest to us reflects a 
situation of strong implication in which the consumer treats information streamed by ads in an evaluative and rational manner and deduces a more or less positive attitude toward the brand".

This assumption confirms and supports our results as the interviewed adolescents of our survey know about Facebook as they are members and highly involved.

Attitude toward the brand is determined also by attitude toward the message (H3). Accordingly, adolescents develop a positive attitude toward the ad which impacts on their attitude toward the brand. This result confirms the theories which assume that Aad determines Ab. In the case where the message provokes positive emotions, the receiver associates the cuteness of the ad to the site, and then if the message is pleasant, the site automatically is pleasant as well. We conclude that $\mathbf{H} \mathbf{3}$ is retained.

As for the effect of positive emotions on sense of community, our study confirms that the dimensions of "warmth" and "pleasure" positively influence adolescents' sense of community. This validates H4. In this line of thinking, the more adolescents feel joy, pleasure and hope, cheerfulness, the more sense of community is reinforced. Adolescents expressing positive emotions after exposure to an ad will be induced into identifying themselves with the values and experiences of the characters representing their community and reinforcing their emotional attachment to these characters. This is supported by Salten (2000) who confirms the positive link between positive emotions and emotional attachment which a component of sense of community.

As for the effect of sense of community, we notice that it has no positive effect on Aad. Therefore, $\mathbf{H 5}$ is rejected. This means that a Facebook adolescent's sense of community does not determine evaluation of attitude toward the message. This result along the one on the effect of positive emotions on Aad (H1) may be explained by the separate and direct effect of emotions on Aad, i.e. there is room for a cognitive process (like sense of community) to explain this relationship.
The nature of the object targeted by the message (Facebbok) may explain the variable effect on judgments of the ad. The product represents an interest community and therefore tends to trigger affective reactions more cognitive which may be triggered by a basic product for example.

The direct positive effect of sense of community on attitude toward the brand is validated, making $\mathbf{H 6}$ a valid hypothesis. This means that the higher sense of community is, the more positive the judgment of Facebook is. In this regard, sense of belonging and confidence in the community strongly correlates with the image that adolescents have of the site. They like it because it helps them build community connections and live this experience and share the community's value. Then, for studies on positive emotions, sense of community is defined as a determinant of $\mathrm{Ab}$ because of the positive effect it exerts.

Finally, as for the mediating role of sense of community between positive emotions and attitudes, we noticed that there is but an indirect mediation of sense of community between emotions and attitudes toward the brand (H7.2). This result may be explained by valence of emotions; positive affective responses have a direct impact on attitude toward Facebook message alone. This direct impact results from the nature of the ad. This latter did not give explicit reasons for using Facebook, leading receivers to develop a reasoning based on rational grounds, but make them reach for emotions to develop and communicate an image of Facebook in favour of their community. It was an allusive ad whose treatment is purely affective and reveals unconscious and unreasoned factors at play (Chaudhuri and Buck, 1995 in Schwartz David, 2005, p9).

Adolescents member of Facebook do not need strength of their sense of community to positively judge an ad, an assumption confirmed by the rejection of $\mathrm{H} 5$ (positive relationship between SC and Aad). 
As for the mediating role of sense of community in the effect of positive emotions on $\mathrm{Ab}$, it has been validated even if emotions have no impact on Ab. Sense of community positively influences $\mathrm{Ab}$ which is reinforced by positive emotions. This means that the indirect effect alone through sense of community is considered in this relationship. This result is explained by the fact strength of attachment and belonging to Facebook community captures all affective reactions provoked by the ad and influences then evaluation of Facebook.

\section{Conclusion}

The aim of our study is to examine the impact of positive emotions on attitudes toward the brand and message of a community of adolescents. It attempted to understand the role of sense of community in this impact. The results led us to conclude direct and positive effects of positive emotions on attitude toward the message and Facebook sense of community have been observed. Moreover, these emotions had no impact on the evaluation of Facebook. This latter was object of the indirect effects of emotions through sense of community. We concluded then with the mediating effect of sense of community between positive emotions and attitude toward the brand.

These results are encouraging as they help advertisers, who target adolescents' communities, consider and better appraise the effects triggered by their sense of community, belonging needs and group influence in their advertising strategies.

The managerial implication of our study consists therefore of integrating postmodernism into marketing as it helps explain behaviour and more specifically modern adolescent-consumer attitudes.

Despite all these contributions, this study is not without limitations. They relate to both theory and methodology. To solve these limitations, we propose the following perspectives and possible research avenues:
- The theoretical limitations consist essentially of insufficient theoretical support needed to develop our research model. Taking in account the concept of sense of community in a marketing model is an ambitious adventure because currently, and to our knowledge, no study has integrated this variable in marketing and specifically advertising. This compromised the construction of our model.

- The limitations related to the choice of our variables: we have limited our research model to affective variables. We could have added cognitive and connotative behavioural dependent variables for example. We limited ourselves to the study of positive emotions. A comparison with the impact of negative emotions will be interesting to see whether the effect of sense of community will be often the same if the individual is exposed to an emotionally negative message.

- The methodology limitations related to the choice of measurement scales (Anglo-Saxon scales adapted to our context), to data collection (data collection immediate after exposure to the message), and the experimental design (unnatural exposure, not in a real context).

\section{References}

Augou, M. O. (2009). Les Facteurs Explicatifs de l'attachement à la Marque: Cas des Boissons Gazeuses en Tunisie, Faculté des Sciences de Gestion de Jendouba, Consulté en 2011 sur le Site: memoireonline.com

Balcazar, F. (1997). 'The Community Psychologist,' Society for Community Research and Action, Volume 30, N3, July, P1-37.

Ben Yahia, I. (2009). 'Proposition d'une Échelle de Mesure de Sentiment Communautaire Envers une Communauté Virtuelle,' Communications of IBIMA, Volume 10. 
Charbti, M. (2006). 'Rôle de la Publicité dans la Construction Identitaire,' Mémoire de Master, ISG Tunis.

Chikh Ahmed, S. (2003). 'Corps et Publicité: Représentation des Effets Émotionnels dans le Cas d'une Publicité,' Mémoire de Master, ISG Tunis (consulté en 2009 sur le lien :http://www.escpeap.net)

Cova, B. \& Badot, O. (1995). Communauté et Consommation: Prospective Pour un Marketing Tribal, Revue Française de Marketing, N151, P5-17.

De Barnier, V. (2002). "Le Rôle des Émotions sur L'attitude Envers la Marque (Ab): Pour une Médiation Totale de l'attitude Envers le Message (Aad)," Recherches et Applications en Marketing, Volume 17, N 3, P81-99.

Edell, J. A. \& Burke, M. C. (1987). The Power of Feeling in Understanding Advertising Effects, Journal of Consumer Research, Volume 14, December.

Graillot, L. (1998). "Emotions et Comportement du Consommateur," Recherches et Applications en Marketing, Volume 13, N1

McMillan, D. W. \& Chavis, D. M. (1986). Sense of Community: A Definition and Theory, Journal of Community Psychology, Volume 14, January, P 6-23.

Mercanti Guérin, M. (2005). La Créativité Publicitaire Perçue: Modélisation et Impact sur le Processus de Persuasion Publicitaire, Thèse de Doctorat De L'université De Caen.

Merle, A. (2004). Apports du Point de Vue Postmoderne à L'étude des Comportements de Consommation de Groupe: Un Début de Clarification, 2ème Journées Normandes de Recherche Sur la Consommation, Société et Consommation, JAE de Caen, 31 Mars/1er Avril, Wp N677.

Mora, P. \& Moscarola, J. (2009, P4). "La Représentation des Émotions Associées à une Expérience d'achat ou de Consommation de Vin," Consulté le 07/05/2012 sur le site: http://www.lesphinxdeveloppement.fr/pu blic/upload/_FRANCE/pdf/Support/Article setpublications/La_representation_des_em otions_2009.pdf

Moser, K. (1998). "Les Modèles d'effet Publicitaire," Recherches et Applications Marketing, Vol 13, N¹.

Pretty, G. M. H., Andrewes, L. \& Collett, C. (1994). "Exploring Adolescents' Sense of Community and its Relationship to Loneliness," Journal of Community Psychology, Volume 22, Octobre, P346-358.

Rémy, E. (2001). Le Lien Social Dans le Marketing des Services, Revue Française de Marketing, N81.

Reunier, S. (2000). L'influence de la Musique d'ambiance sur le Comportement des Consommateurs sur Les Lieux de Vente, Thèse de Doctorat en Sciences de Gestion, Centre DMSP, Université Paris IXDauphine.

Riou, N. (2003). Quand la Publicité Devient Postmoderne, Revue Française de Marketing, N 192-193.

Roussel, P. et al. (2002). Méthodes d'équations Structurelles, Recherches et Applications En Gestion, Paris, Economica.

Schwartz, F. D. (2005). 'Pourquoi S'intéresser aux Émotions quand on S'intéresse aux Mécanismes Socio-Cognitifs à l'oeuvre dans les Phénomènes Persuasifs?,' Consulté En 2009 Sur Le Lien: http:/urp-scls.ustrasbg.fr/schwartzdavid.pdf

Steinberg, L. \& Morris, A. S. (2001). "Adolescent Development," Annual Review of Psychology, Volume 52, Research Library P83-110.

Tartaglia, S. (2006). "A Preliminary Study for a New Model of Sense of Community," Journal of Community Psychology, Volume $34, \mathrm{~N}^{\circ} 1$.

Vieno, A., Santinello, M., Pastore, M. \& Perkins, D. (2007). "Social Support, Sense of Community in School and Self Efficacy as 
Resources during Early Adolescence: An Integrative Model," American Journal of Community Psychology, Volume 39, P 177190.

Wendy, W. (2000). "Attitude Change: Persuasion and Social Influence," Annual Review of Psychology, Volume 51, Research Library P539-570.
Zhao, X., Lynch, J. G. \& Chen, Q. (2009). Reconsidering Baron and Kenney: Myths and Truths about Mediation Analysis, Journal of Consumer Research, June, Manuscript \#08-0083-2 Consulté Sur Internet En 2013. 